Egypt. J. of Nutrition and Health Vol. 15 No. 2 July (2020)

\title{
Effect of quinoa (Chenopodium quinoa) on Lipid Profile in Rats Exposed to twoSynthetic Food colors
}

\author{
Rasha M. Bahnasy ${ }^{1}{ }^{2}$ and Eman M. Ragheb ${ }^{3}$ \\ ${ }^{1}$ Nutrition and Food Science Dept. Faculty of Home Economics \\ Al- Azhar University, Egypt \\ ${ }^{2}$ Home Economics Dept. Faculty of Arts and Science-Rafha Northern Border \\ University, KSA \\ ${ }^{3}$ Regional Center for Food and Feed (RCFF), Agriculture Res. Center, Giza, Egypt
}

\begin{abstract}
Increasing scientific evidence suggests potential adverse effects on children's health from synthetic chemicals used as food additives. Synthetic food colors are food additives are widely used as colorants in food. This study was conducted to investigate the effectiveness of quinoa powder as nutraceuticals on lipids profile for young experimental rats exposed to chronic administration of synthetic food colores (azo dyes),chocolate brown (CH) or sunset yellow (SY). Seventy healthy young male albino rats "Sprague Dawley" strain weighing $(90 \pm 10 \mathrm{~g})$, were used and divided randomly into two main groups; the first main group ( $\mathrm{n}=10$ rats) was kept as (-ve) control group and fed on basal diet. The second main group ( $\mathrm{n}=60$ rats) were divided into 6 sub-groups (equal groups) and fed on basal diet as follow: The first three subgroups were fed on chocolate brown oral dose $(0.3 \mathrm{mg} / \mathrm{kg}$ b.wt.) one was kept as a (+ve) control group, while the other two subgroups were fed on quinoa as powder mixed with the basal diet $(5 \%, 10 \%$ respectively) as replacement from starch. The other three subgroups were fed on SY oral dose (2.5 mg/kg b.wt.) one was kept as a(+ve) control group, while the other two subgroups were fed quinoa as powder mixed with the basal diet (5\%,10\%respectively) as replacement from starch. At the end of the experiment (56 days), feed intake ( $\mathrm{FI}$ ), body weight gains (BWG\%), feed efficiency ratio (FER)were finally calculated. Rats were sacrificed and relative weights of livers, kidneys, hearts, spleens were calculated, blood samples were collected for biochemical analysis: T.C, T.G, LDL-C,VLDL-C and HDL-C. Moreover, histopathological changes of hearts were examined. The results indicated that chronic administration of synthetic food colors $\mathrm{CH}$ or SY recorded significant changes for all above biochemical parameters. While the treatment with quinoa powder revealed significant improvement in all of them. Histopathological examination supported these findings. It could be concluded that quinoa was effective in treatment dysfunction induced by azo dyes. This effect may be due to high content of phenolic compounds in quinoa.
\end{abstract}

Key wards:azo dyes, chocolate brown, sunset yellow, quinoa, lipids profile.

\section{Introduction}

Increasing scientific evidence suggests potential adverse effects on children's health from synthetic chemicals used as food additives, both those deliberately added to food during processing (direct) and those used in materials that may contaminate food as part of packaging or manufacturing (indirect) reported by Trasande et al., (2018). 


\section{Rasha M. Bahnasy, et al}

Azo dyes are kind of food additives which are widely used as colorants in food (Al-Shinnawy \& Elkattan, 2013). Azo colors are characterized by azo groups $(\mathrm{N}=\mathrm{N})$ bound to aromatic rings in their molecular structures (Demirkol et al., 2012).Azo dyes can induce chromosomal aberrations in mammalian cells and cause DNA damage in the colon of mice. They also induce moderate conformational perturbations in the secondary structure of DNA after binding with DNA in media components containing glucose leading to the formation of the toxic components (Basu \& Suresh Kumar, 2014).

Among the food dyes which are widely used is chocolate brown dye (HT). as one type of azo(Aguilar et al., 2014).Chocolate brown is a synthetic bis-azo dye composed of tartrazine, carmoisine and brilliant blue FCF(Sharma et al., 2005).It is a brown-colored, water soluble dye which is used to enhance the color in several food products such soft drinks, candies, ice-creams and beverages(Nollet\& Toldrá, 2012).

Another famous synthetic food dyes is sunset yellow FCF (E110) which belongs to the family of azo dyes and widely used in food industry. However, Sunset yellow has positive and negative effects as well, by giving attractive physical appearance and consumer acceptance. At the same time, it can cause as attention deficit hyperactivity disorder (ADHD), is a group of behavioral symptoms that include inattentiveness, hyperactivity and impulsiveness, cancer and some other health effects with an excess consumption(Rovina et al., 2016).

A whole grain product has increased during the last decade due to the known benefits associated with their consumption. These benefits include reduction in the risk of suffering stroke, diabetes, heart disease, asthma and colorectal cancer, and other benefits include better weight management, healthier carotid arteries and better blood pressure levels (Aune et al., 2011).

Quinoa (Chenopodium quinoa Willd.) is a pseudocereal traditionally consumed by Andean cultures that is attracting attention worldwide as a functional food (Ahmed et al., 2018).Quinoa, just one single plant, could meet the basic nutritional needs of the human body and is officially recommended by (FAO) as the most suitable food for human consumption because of its "full nutrition." Therefore, it was listed as one of the world's ten healthiest nutritional foods. Quinoa is not only rich in protein, fatty acids, and minerals but also rich in numerous phytochemicals including saponins, phytosterols, phytoecdysteroids, phenolics and bioactive peptides. These compounds may exert beneficial effects on metabolic, cardiovascular, and gastrointestinal health.It plays a very important role in both preventing and treating diseases and maintaining human health.(Wang et al., 2019)demonstrate significant increases in T.G with chocolate brown $121 \%$, significant decrease in HDL-C with chocolate brown $94 \%$.

\section{Aim of the study:}

This research was conducted to evaluate the effect of quinoa on lipids profile in young male albino rats exposed to chronic administration of azo dyes ; (chocolate brown( HT)or sunset yellow(SY). 


\section{Egypt. J. of Nutrition and Health Vol. 15 No. 2 July (2020)}

\section{Materials and Methods}

Materials

Experimental animals:

Seventy healthy young male albino rats "Sprague Dawley" strain of an average body weight $(90 \pm 10 \mathrm{~g})$ were used. They were obtained from the laboratory animal colony, Helwan Farm, Vaccine and Immunity Organization, Cairo, Egypt.

\section{Chemicals and other materials:}

Casein ">85\% protein", vitamins mixture, minerals, corn starch, DL-methionine, choline chloride, cellulose and Kits were purchased from El-Gomhoria Company for Chemicals and Drugs, Cairo, Egypt. Food Colors were purchased fromMisr Food Additives - MIFAD Company, Badr City, Cairo, Egypt. Quinoa (Chenopodium quinoa) was purchased from the Agriculture Seeds, Herbs and Medicinal Plants Company, Cairo, Egypt.

\section{Methods}

\section{Preparation of Quinoa}

Quinoa (Chenopodiumquinoa) was cleaned manually to remove the broken grains, dust and other material, then washed with purified water and drained. Quinoa was dried under shade at room temperature then crushed into fine powder using electric blender Moulinex type LM 240. Then it was kept in dark glass containers in the refrigerator until use with basal diet.

\section{Experimental diet:}

Basal diet was prepared from fine ingredients per $100 \mathrm{~g}$ according to (Reeves et al., 1993) as follow: casein ( $\geq 85 \%$ protein) $14 \%$, corn oil $4 \%$, cellulose $5 \%$, choline chloride $0.25 \%$, DL-methionine $0.3 \%$, salt mixture $3.5 \%$ according to (Hegsted et al., 1941).vitamins mixture $1 \%$ according to(Campbell, 1963) and corn starch up to $100 \mathrm{~g}$.

Normal young male albino rats received daily dose of azo dyes (chocolate brown or sunset yellow) during the experimental period as following:

Chocolate brown HT dye (E155) received at a dose of " $0.3 \mathrm{mg} / \mathrm{kg}$ body weight" (b.wt.) mixed with diet according to (Hassan, 2010)equal 3mg/kg diet.

Sunset yellow FCF dye (E110) received at a dose of " $2.5 \mathrm{mg} / \mathrm{kg}$ body weight" (b.wt.) mixed with dietaccording to(Fouad et al., 2013).equal $25 \mathrm{mg} / \mathrm{kg}$ diet.

\section{Experimental design:}

All rats were fed on basal diet for one week before starting the experiment for adaptation. After this week, they weredivided randomly into two main groups; the first main group ( $n=10$ rats) was kept as (-ve) control group, fed on basal diet only. The second main group ( $n=60$ rats) were divided into 6 sub-groups (10 rats each): The first three subgroups were fed on chocolate brown dose $(0.3$ $\mathrm{mg} / \mathrm{kg}$ b.wt.) daily, one subgroup was kept as a (+ve) control group, while the other groups were fed on the Quinoa powder mixed with the basal diet (5\%, 10\% respectively) as replacement from starch. The other three subgroups were fed on SY dose $(2.5 \mathrm{mg} / \mathrm{kg}$ b.wt.) one was kept as a(+ve) control group, while the other two subgroups were fed on Quinoa as powder mixed with the basal diet $(5 \%, 10 \%$ respectively) as replacement from starch. During the experimental period (56 days), the quantities of diet consumed and / or wasted were recorded every day. In addition, rats' body weights were recorded at the beginning, weekly and at the end. At the end of experimental period, the rats were fasted overnight before being sacrificed and blood samples were collected from each rat (from hepatic portal vein) then centrifuged for 15 minutes at 3000 revolutions per minute "r.p.m." to obtain the serum. 


\section{Rasha M. Bahnasy, et al}

Serum was carefully separated and transferred into dry clean Eppendorf tubes by using Pasteur pipette and kept frozen at $\left(-20^{\circ} \mathrm{C}\right)$ till analysis as described by(Schermer\& Schermer, 1967).

\section{Biological evaluation}

At the end of the experiment, feed Intake (FI), body Weight Gain \% (BWG \%), Relative organs weight \% (ROW\%) and Feed Efficiency Ratio (FER) were calculated according to (Chapmanet al., 1959).

\section{Biochemical analysis of serum:}

Total cholesterol was determined in the serum according to the method described by(Allain et al., 1974).Triglycerides were determined in the serum according to the method described by(Trinder \& Ann, 1969).HDL-C was determined in the serum according to the method described by(LopesVirella et al., 1977).Serum VLDL-C was calculated according to(Friedwald et al. , 1972).

Serum LDL-C was calculated according to(Friedwald and Fredrickson, 1972).

\section{Histopathological examinations}

For Hearts of sacrificed rats were done according to (Drury \& Wallington, 1980).

\section{Statistical analysis}

Statistical analysis was carried out using the program of Statistical Package for Social Sciences (SPSS), PC statistical software (Version 20; Untitled-SPSS Data Editor). The results were expressed as Mean \pm Standard deviation (SD).Data were analyzed using one-way classification, analysis of variance (ANOVA) test according to (Arrnitage \& Berry, 1987).followed by Duncan's multiple range test. The differences between means were tested for significance using least significant difference (LSD) test at level of $P<0.05$ (Snedecor\& Cochran, 1980).

\section{Results and Discussion}

\section{Effect of quinoa on FI, BWG \% and FER for Rats Exposed to two synthetic food colors}

As shown in table (1) feed intake(FI) (g/day), body weight gain(BWG) and feed efficiency ratio(FER) recorded significant decrease in the (+ve) control chocolate brown group, when compared to the (-ve) control group. All experimental groups treated with quinoa powder $5 \%, 10 \%$ showed significant increase in body weight gain and feed efficiency ratio when compared with the (+ve) control group. The best results were recorded for the groups treated with quinoa $5 \%$ which recorded the nearest values to the (-ve) control group. Also, results of $\mathrm{FI}$ (g/day) recorded significant decrease in the (+ve) control sunset yellow group compared to (-ve) control group.

It was noticed that after administration of colorants, rats became more active, nervous and aggressive.In this respectAjiboye et al., (2011)mentioned the role of free radicals which result from the dye have an effect on cells, tissues as well as liver, disorder in metabolism, all of these may cause reduce in weight. The reduction in body weight is likely due to the degradation of proteins, fats and dysfunction of organs caused by oxidative stress and fat oxidation(Vanaja and Palanimuthu, 2014).

Also Abdel-Rahim et al., (2019) demonstrated highly noticeable decrease in the food intake ,body weight gain, and feed efficiency of mice fed on synthetic color compared to the control group, while these parameters showed non-significant with natural color.

BWG (\%) recorded significant decrease in (+ve) control chocolate brown group and (+ve) control sunset yellow group when compared to (-ve) control group. Results of FER recorded significant 


\section{Egypt. J. of Nutrition and Health Vol. 15 No. 2 July (2020)}

decrease in the (+ve) control chocolate brown group and (+ve) control sunset yellow group when compared to (-ve) control group.Also, dietary dyes generate free radicals that cause damage to the DNA and other problems in the body that leads to decrease in body weight (Hassan, 2010).

The observed significant reduction of $\mathrm{FI}, \mathrm{BWG}$ and FER in rats treated with chocolate brown is consistent with previous reports for Abbas \& Al-Hamadawi,( 2019) who concluded that using of chocolate brown dye in various foods reduced body weight The obtained results agreed with other studies that recorded marked decrease in the body weight of experimental animals which treated with brownish chocolate dye (Neshe et al., 2016), also other food azo dyes have a similar effect(ALShinnawy, 2009). On the other hand, the results in the present study disagreed with (Abd Elhalem et al., 2016).who reported that dietary treatment of sunset yellow (SY) for 13 weeks caused slight increase in body weight and at body weight gains at the low dose of SY. A similar finding was also reported by (Elbanna et al., 2017)who revealed that the rats fed either sunset yellow (E110) and carmoisine (E122) or their degradation products exhibited a significant increase in body weight, with percentages ranging from $2.14 \%$ to $4.04 \%$ compared to the control group. These findings similar to(Helal et al., 2000).

The results are in harmony with those (Lamiaa \& Barakat, 2011; Vega- Gálvez et al., 2010)they showed that consumption of quinoa plays a role in regulating energy homeostasis and maintain body weight balance. Moreover, they indicated that the quinoa is an excellent example of functional food that aims to improve nutrient intakes and lower body weight and possibly reducing the risk of various diseases. Also, this study disagrees with(Halaby et al., 2017)who recorded significant decrease values $(P<0.05)$ in BWG, $F I$ and FER as compared to the positive control group (hypercholesterolemia), it seems that quinoa gave protection effect against overweight.

Table (1):

Effect of quinoa on feed intake (FI), body weight gain(BWG) \% and feed efficiency ratio (FER) for rats exposed to two synthetic foodcolors

\begin{tabular}{c|c|c|c|c|c}
\hline Groups & Fl(g)/day & IBW $(\mathrm{g})$ & FBW $(\mathrm{g})$ & BWG $(\%)$ & FER \\
\hline$(-$ ve $)$ Control & $23.9 \pm 1.70^{\mathrm{a}}$ & $132.2 \pm 15.7^{\mathrm{a}}$ & $272.6 \pm 13.6^{\mathrm{a}}$ & $108.2 \pm 24.1^{\mathrm{a}}$ & $0.126 \pm 0.02^{\mathrm{a}}$ \\
\hline$(+$ ve)Control CH) & $19.81 \pm 1.61^{\mathrm{c}}$ & $132.6 \pm 12.9^{\mathrm{a}}$ & $221.8 \pm 13.1^{\mathrm{c}}$ & $67.77 \pm 7.2^{\mathrm{c}}$ & $0.085 \pm 0.008^{\mathrm{c}}$ \\
\hline Quinoa 5\% (CH) & $21.43 \pm 2.57^{\mathrm{b}}$ & $131.8 \pm 23.2^{\mathrm{a}}$ & $250 \pm 14^{\mathrm{ab}}$ & $93.01 \pm 24.9^{\mathrm{b}}$ & $0.111 \pm 0.026^{\mathrm{ab}}$ \\
\hline Quinoa 10\% CH) & $22.58 \pm 2.39^{\mathrm{ab}}$ & $131.8 \pm 21.5^{\mathrm{a}}$ & $249.8 \pm 18.9^{\mathrm{ab}}$ & $92.1 \pm 22.5^{\mathrm{b}}$ & $0.110 \pm 0.022^{\mathrm{ab}}$ \\
\hline (+ve ) Control (SY) & $18.83 \pm 2.43^{\mathrm{c}}$ & $132.4 \pm 19.4^{\mathrm{a}}$ & $223.4 \pm 19.7^{\mathrm{c}}$ & $69.8 \pm 9.4^{\mathrm{c}}$ & $0.087 \pm 0.010^{\mathrm{c}}$ \\
\hline Quinoa 5\% (SY) & $22.59 \pm 3.66^{\mathrm{ab}}$ & $132.2 \pm 27.6^{\mathrm{a}}$ & $254.8 \pm 40.2^{\mathrm{b}}$ & $94.9 \pm 20.2^{\mathrm{ab}}$ & $0.113 \pm 0.020^{\mathrm{ab}}$ \\
\hline Quinoa 10\% (SY) & $23.15 \pm 4.29^{\mathrm{a}}$ & $134.4 \pm 21.7^{\mathrm{a}}$ & $250 \pm 24.65^{\mathrm{ab}}$ & $88.02 \pm 21.5^{\mathrm{b}}$ & $0.106 \pm 0.022^{\mathrm{b}}$ \\
\hline
\end{tabular}

IBW $=$ initial body weight FBW $=$ final body weight Data expressed as mean \pm SD

Different superscript letters in the same column denote significant differences $P<0.05$ ).

Effect of quinoa on relative organs weight \% (liver, kidney, heart and spleen) for rats exposed to the two synthetic food colors

As shown in table (2) the relative liver weight (\%) showed significant increase in the mean value of the (+ve) control chocolate brown group, when compared to (-ve) control group. All treated groups showed significant decrease in relative liver weight (\%) when compared with the (+ve) control group. The best results were recorded for the group treated with quinoa $10 \%$, which recorded the nearest valuetothe (-ve) control group. 


\section{Rasha M. Bahnasy, et al}

Results of relative liver weight (\%) recorded significant increase in the mean value of the (+ve) control sunset yellow group, compared with the (-ve) control group. All treated groups showed significant decrease in relative liver weight (\%) when compared with the (+ve) control group. The best results were recorded for the group treated with quinoa $10 \%$.

The relative kidney weight (\%) showed significant increase in the mean value of the (+ve) control chocolate brown group, compared with the (-ve) control group. All treated groups showed significant decrease in relative kidney weight (\%) when compared with the (+ve) control group. The best result was recorded for the group treated with quinoa $5 \%$.

Also, the relative kidney weight (\%) showed significant increase in the mean value of the (+ve) control sunset yellow group compared to the (-ve) control group. All treated groups showed significant decrease in relative kidney weight (\%) when compared with (+ve) control group. The treatment with $5 \%$ and $10 \%$ show no significant difference compared with the (-ve) control.

The mean value of the relative heart weight (+ve) control chocolate brown group showed significant increase when compared with the (-ve) control group. All treated groups showed significant decrease in relative heart weight (\%) compared with the (+ve) control group. The best results were recorded for the group treated with quinoa $10 \%$.

On the other hand, relative heart weight (\%) recorded significant increase in the mean value of the (+ve) control sunset yellow group, compared with the (-ve) control group, all treated groups showed significant decrease in relative heart weight (\%) when compared with the (+ve) control group. The best result was recorded for the group treated with quinoa $10 \%$.

Regarding the relative spleen weight (\%), it showed significant increase in the mean value of the (+ve) control chocolate brown group, compared to the (-ve) control group, all treated groups showed significant decrease in relative spleen weight (\%) when compared with (+ve) control group. The best result was recorded for the group treated with quinoa $10 \%$, which recorded the nearest value to the (-ve) control group.

The relative spleen weight (\%) recorded significant increase in the mean value of the (+ve) control sunset yellow group, compared to (-ve) control group, all treated groups showed significant decrease in relative spleen weight (\%) when compared with the (+ve) control group. The best results were recorded for the group treated with quinoa $10 \%$.

Measurement of the relative liver body weight changes denotes the changes in liver size which is an expression of the pathology in organ (Zakaria et al., 2017).

The previous findings of this study are in agreement with (Hassan, 2010)who showed that a significant increase was observed in the relative weight of heart rats fed on tartrazine or chocolate brown. Also, there was an increase in spleen relative weight of groups treated with the high level of tartrazine and chocolate brown. However, the high level of tartrazine and the two levels of chocolate brown produced a significant decrease in the relative weight of the liver and this result disagree with the result of the present study.

On the other hand, these results disagreed with that of Neshe et al., (2016)who showed that chocolate brown dye insignificantly increased the average weight of heart of the test animals for both 


\section{Egypt. J. of Nutrition and Health Vol. 15 No. 2 July (2020)}

concentrations. While the average weight of kidney was increased only in case for high concentrations group in comparison with control group.

The change of relative organs weight is a sign of toxicity. Thus to rat diet chocolate brown dye must have considerable toxicity on the respective organs of the test animals(Mehedi et al., 2013).

While, the results of this study agreed with that of Salman, (2016)who showed that the result of use for three doses of chocolate brown dye recorded a significant increase in liver weight for all treatments compared with the control group. The obtained increase in liver weight responded to a case of poisoning; as a center to metabolize poisons and drugs, as well as free radicals, which consists by azo dyes, which may cause damage in fabric of the liver and thus amplified (Demirkol et al., 2012).

On the other hand, the results of this study are similar to the results reported by MA, (1995) who found that oral ingestion of synthetic dyes such Fast Green and Sunset Yellow for 30 days in mice increased the liver and kidney weights.

Also, the results of the present study agreed with Sahar SA \& Manal MEM, (2012)who noticed that, during the administration period (13 weeks) of coloring foods, rats become more active (hyperactive) and aggressive. Also, rats showed that the skin become reddish and irritating after administration of color fruit juice for 6 and 12 hours. These results are in agreement with (Helal et al., 2000) who proved that food colorants (fast green, annatto and sunset yellow) caused many signs of behavior variation like hyperactivity, nervous motion and become aggressive. Also, after administration of sunset yellow caused skin irritation.

Abdel-Rahim et al., (2019) demonstrated a significant increase in the average weight of the major organs liver, spleen, heart, pancreas and kidney of the group of mice treated with chocolate brown.

Table (2):

Effect of quinoa on relative organs weight \% (liver, kidney, heart and spleen) for rats exposed to two synthetic food colors

\begin{tabular}{l|c|c|c|c}
\hline \multirow{2}{*}{ Groups } & \multicolumn{4}{|c}{ Relative organs weight \% } \\
\cline { 2 - 5 } & Liver & Kidney & Heart & Spleen \\
\hline (- ve ) Control & $2.33 \pm 0.12^{\mathrm{b}}$ & $0.55 \pm 0.07^{\mathrm{c}}$ & $0.28 \pm 0.04^{\mathrm{c}}$ & $0.29 \pm 0.06^{\mathrm{c}}$ \\
\hline (+ve)Control $(\mathrm{CH})$ & $3.07 \pm 0.25^{\mathrm{a}}$ & $0.75 \pm 0.04^{\mathrm{a}}$ & $0.43 \pm 0.09^{\mathrm{a}}$ & $0.42 \pm 0.04^{\mathrm{a}}$ \\
\hline Quinoa 5\% (CH) & $2.76 \pm 0.44^{\mathrm{ab}}$ & $0.64 \pm 0.06^{\mathrm{b}}$ & $0.37 \pm 0.05^{\mathrm{ab}}$ & $0.36 \pm 0.05^{\mathrm{b}}$ \\
\hline Quinoa 10\% (CH) & $2.33 \pm 0.30^{\mathrm{b}}$ & $0.65 \pm 0.08^{\mathrm{b}}$ & $0.32 \pm 0.06^{\mathrm{b}}$ & $0.31 \pm 0.04^{\mathrm{bc}}$ \\
\hline (+ ve) Control (SY) & $2.88 \pm 0.21^{\mathrm{a}}$ & $0.72 \pm 0.13^{\mathrm{a}}$ & $0.40 \pm 0.13^{\mathrm{a}}$ & $0.40 \pm 0.09^{\mathrm{a}}$ \\
\hline Quinoa 5\% (SY) & $2.77 \pm 0.43^{\mathrm{ab}}$ & $0.61 \pm 0.07^{\mathrm{b}}$ & $0.35 \pm 0.11^{\mathrm{b}}$ & $0.34 \pm 0.06^{\mathrm{b}}$ \\
\hline Quinoa 10\% (SY) & $2.74 \pm 0.36^{\mathrm{ab}}$ & $0.67 \pm 0.09^{\mathrm{b}}$ & $0.34 \pm 0.11^{\mathrm{b}}$ & $0.32 \pm 0.05^{\mathrm{bc}}$ \\
\hline
\end{tabular}

Data expressed as mean \pm SD

Different superscript letters in the same column denote significant differences $P<0.05$ ). 


\section{Rasha M. Bahnasy, et al}

\section{Effect of quinoa on lipids profile forrats exposed to the synthetic food colors.}

Table (3) illustrates the change in lipid profile for the controls and treated groups. Results of T.C recorded significant increase in the mean value of the (+ve) control chocolate brown group when compared with the (-ve) control group. All experimental groups treated with quinoa as powder $5 \%, 10 \%$ recorded significant decrease in T.C. The best result of T.C were recorded for the group treated with quinoa $10 \%$.

Also, results of T.C $(\mathrm{mg} / \mathrm{dl})$ recorded significant increase in the mean value of the $(+\mathrm{ve})$ control sunset yellow group when compared to (-ve) control group. All experimental groups treated with quinoa as powder $5 \%, 10 \%$ recorded significant decrease in T.C $(\mathrm{mg} / \mathrm{dl})$. The best results for T.C were recorded by the group treated with quinoa $5 \%$.

Results of T.G (mg/dl) recorded significant increase in the mean value of the $(+v e)$ control chocolate brown group when compared to (-ve) control group. All experimental groups treated with quinoa as powder $5 \%, 10 \%$ recorded significant decrease in T.G (mg/dl). The best result for T.G were recorded by the group treated with quinoa $5 \%$ as the nearest values from (-ve) control group.

Also, results of T.G $(\mathrm{mg} / \mathrm{dl})$ recorded significant increase in the mean value of the $(+\mathrm{ve})$ control sunset yellow group compared with the (-ve) control group. All experimental groups treated quinoa as powder $5 \%, 10 \%$ recorded significant decrease in T.G $(\mathrm{mg} / \mathrm{dl})$. Both results recorded non- significant difference with the (-ve) control group.

Data of HDL-c, LDL-C and VLDL-c in table (3) illustrated the change in controls and treated groups. Results of $\mathrm{HDL}-\mathrm{c}(\mathrm{mg} / \mathrm{dl})$ recorded significant decrease in the mean value of the (+ve) control chocolate brown group when compared to (-ve) control group. All experimental groups treated with quinoa as powder $5 \%, 10 \%$ recorded significant increase in HDL-c. The best result for HDL-c was recorded by the group treated with quinoa $10 \%$ which recorded non- significant difference with the (-ve) control group.

Also, results of HDL-c recorded significant decrease in the mean value of the (+ve) control sunset yellow group when compared with the(-ve) control group.All experimental groups treated with quinoa as powder $5 \%, 10 \%$ recorded non- significant difference with the (+ve) control group.

Regarding LDL-c recorded significant increase in the mean value of the (+ve) control chocolate brown group when compared with the (-ve) control group. All experimental groups treated with quinoa as powder $5 \%, 10 \%$ recorded significant lower values in LDL-c than the (+ve) control. The best result for LDL-cwas recorded by the group treated with quinoa $10 \%$ which showed non- significant difference with the (-ve) control group.

Also, results of LDL-c recorded significant increase in the mean value of the $(+v e)$ control sunset yellow group when compared to (-ve) control group. All experimental groups treated with quinoa as powder $5 \%, 10 \%$ recorded significant decrease in LDL-c. The best result for LDL-c was recorded by the group treated with quinoa $5 \%$.

Concerning the mean value $\pm S D$ of VLDL-c $(\mathrm{mg} / \mathrm{dl})$ recorded significant increase in the mean value of the (+ve) control chocolate brown group when compared to the (-ve) control group. All experimental groups treated with quinoa as powder $5 \%, 10 \%$ recorded significant decrease in VLDL-c $(\mathrm{mg} / \mathrm{dl})$. There was no significant difference between group of rats treated with quinoa as powder $5 \%$ and $10 \%$. 


\section{Egypt. J. of Nutrition and Health Vol. 15 No. 2 July (2020)}

Also, results of VLDL-c(mg/dl) recorded significant increase in the mean value of the (+ve) control sunset yellow group when compared with the(-ve) control group. All experimental groups treated with quinoa as powder 5\%, 10\% recorded significant decrease in VLDL-cwith no significant difference between the two groups.

In this respect Plasma HDL-c plays a critical role in cholesterol metabolism in vivo. HDL-c particles mediate the transport of cholesterol from peripheral tissues to the liver in a process termed reverse cholesterol transport, which is believed to play a critical role in whole-body cholesterol homeostasis (Johnson et al., 1991).

The result of this study correspond previous research report for Aboel-Zahab et al., (1997) who found significant increase in serum total lipids, cholesterol and triglycerides in rats fed with chocolate colors A and B that contained Tartrazine and Carmoisine (sunset yellow, Tartrazine, Carmoisine and brilliant blue) in varying concentrations.(El-Malky et al., 2014)showed that administration of synthetic colors in overdose leads to significant increase in the lipid profile of rats including total cholesterol, LDL and HDL.

Similar types of results were also demonstrated by (Sahar\& Manal, 2012)which substantiate the authenticity of this work. In the present study, administration of sunset yellow resulted in significant increase in T.C, TG, LDL-C and VLDL-C in rats treated with sunset yellow these results are in agreement with the recorded data of (Tawfek et al., 2015) who found that consumed sunset yellow exhibited a significant increase in total cholesterol, and total lipids but disagree with their result for LDL because they showed a non-significant effect on LDL-c. Because blood lipids values were significantly increased in all case groups. These effects of sunset yellow on the lipid profile maybe due to imbalances between normal rates of fat metabolism and secretion. The possible explanation of these observed increments may reside in the direct or indirect action of these food additives on lipid metabolism or lipid peroxidation.

Abdel-Rahim et al., (2019) demonstrated the changes in serum total cholesterol level, Tlipid, LDL and VLDL levels in mice fed biscuits incorporated with natural dyes, synthetic dyes or mixture of them. No significant $(P \geq 0.05)$ differences in total cholesterol level, $T$-lipid, LDL and VLDL between the control group and these groups fed with natural dyes were observed. However, significant increases in T.G with chocolate brown $121 \%$, significant decrease in HDL-C with chocolate brown $94 \%$.

Dietary fiber is used more frequently in the treatment of diabetes, hypercholesterolemia, and diverticulitis through its effect on gastrointestinal function and reduction of LDL-C in hypercholesterolemic animals (EI Rabey et al., 2013). In combination, these plant food components may have a very significant impact on blood lipids and cardiovascular disease, which appeared to be complications of hypercholesterolemia (Fulgoni et al., 2013).

In the current study, feeding rats on azo dyes in the diet for 56 days increased the serum T.C, T.G, LDL-C and VLDL-C and decreased HDL in the positive control group. Administration of quinoa caused significant improvement in serum lipid profile parameters. A possible underlying mechanism for this quinoa effect may be based on bile acid activity. In an in-vitro essay it was shown that quinoa proteins have a higher bile acid-binding capacity affecting the absorption of lipids (Takao et al., 2005). 


\section{Rasha M. Bahnasy, et al}

Other approaches, such as increased dietary fiber intake, have been associated with improvement in lipid profile in a number of randomized clinical trials (Hu et al., 2013).Mbikay, (2012) revealed that, these essential nutrients including (polyphenols and flavonoids) are a potent antioxidant with multiple therapeutic properties. Anti-dyslipidemic properties are more evident as its dietary supplementation has been shown also, to significantly reduce plasma TC and TG (cardiovascular prevention), anti-allergic, anti-inflammatory, antiviral, anti-carcinogenic, hypotensive, and anti-diabetic effects in the obese rat model of metabolic syndrome.

Bile acid emulsification of fats constitutes an essential step of intestinal lipid absorption. A reduction in intestinal dietary fat absorption observed through the increase in lipid content in the feces was reported in rodents fed a diet containing quinoa protein extract and a quinoa extract enriched with 20-hydroxyecdysone (Foucault et al., 2014).Although human studies are inconclusive, some authors argued that quinoa has an enhanced content of soluble and in-soluble fiber compared with other cereals and grains, dietary fiber may have an important role in hepatic cholesterol synthesis linked to bile acid regulation(Lamothe et al., 2015). These findings are in agreement with (Bastidas et al., 2016) who published that quinoa is a more effective functional food, in terms of a source of bioactive flavonoids, than conventional cereal and pseudo cereal grains.

This study in agreement with (Halaby et al., 2017) who studied protective influence of Quinoa on hypercholesterolemia in male rats and reported that the positive control group has shown a significant increase $\mathrm{P}<0.05$ in the mean values of TC; TG; LDL-C and VLDL-C when compared with the negative control group. On the contrary, raised level of HDL-c was associated with reduced risk of atherosclerosis, since high density lipoprotein in serum is thought to facilitate the translocation of excess cholesterol from the peripheral tissue to liver for further catabolism (Makni et al., 2008).

Furthermore, the obtained results agreed with (Wang et al., 2012) who stated that the increase in HDL-c ratio is one of the most important criteria of anti-hypercholesterolemia agent. Rats which were fed on high-cholesterol diet with two various levels from quinoa had lower mean values of lipid profile compared with positive control group might be due to decrease of cholesterol absorption and biosynthesis and increase of faecal bile acid and cholesterol excretion. The data were in the line with those of Zevallos et al., (2014).

Some recent studies explained the role of quinoa in reducing blood lipids, in this respect, Joaquin et al., (2020) studied the hydrolysis of saponin-rich extract from quinoa and its pancreatic lipase inhibitory activity and hypocholesterolemic effect, they concluded that sapogenin standards exhibited no bioactivities, protodioscin and hederacoside $\mathrm{C}$ slightly inhibited the lipase (around $10 \%)$ and protodioscin reduced the bio accessible cholesterol $(23 \%$ reduction, $p=0.035)$.

Also, Pourshahidi et al., (2020) concluded that consumption of quinoa, in the form of novel biscuits, produces favorable (i.e. decreased), albeit moderate changes in total cholesterol and LDL cholesterol concentrations, compared to control (wheat) biscuits over a 4-week period. Regular consumption of quinoa may contribute to lowered cardio vascular disease risk in freeliving older adults. 


\section{Egypt. J. of Nutrition and Health Vol. 15 No. 2 July (2020)}

Moreover, Yanan et al., (2020) demonstrated that quinoa polysaccharide supplementation could ameliorate the hyperlipidemia induced by HFD in association with modulating gut micro biota in a positive way.

Table (3):

Effect of quinoa on lipid profile for rats exposed to the two synthetic food colors Data expressed as mean \pm SD

\begin{tabular}{c|c|c|c|c|c}
\hline Groups & $\begin{array}{c}\text { Total cholesterol } \\
(\mathrm{mg} / \mathrm{dl})\end{array}$ & $\begin{array}{c}\text { Triglycerides } \\
(\mathrm{mg} / \mathrm{dl})\end{array}$ & HDL-C $(\mathrm{mg} / \mathrm{dl})$ & LDL-C $(\mathrm{mg} / \mathrm{dl})$ & VLDL-C $(\mathrm{mg} / \mathrm{dl})$ \\
\hline$(-\mathrm{ve})$ Control & $78.75 \pm 3.34^{\mathrm{e}}$ & $76.00 \pm 11.36^{\mathrm{c}}$ & $39.20 \pm 3.11^{\mathrm{a}}$ & $24.35 \pm 5.56^{\mathrm{c}}$ & $15.2 \pm 2.27^{\mathrm{c}}$ \\
\hline$(+\mathrm{ve})$ Control $(\mathrm{CH})$ & $121.50 \pm 11.79^{\mathrm{a}}$ & $111.30 \pm 3.87^{\mathrm{a}}$ & $33.60 \pm 3.13^{\mathrm{c}}$ & $66.20 \pm 8.53^{\mathrm{a}}$ & $21.7 \pm 1.50^{\mathrm{a}}$ \\
\hline Quinoa 5\% (CH) & $96.00 \pm 4.53^{\mathrm{c}}$ & $87.40 \pm 6.02^{\mathrm{b}}$ & $35.00 \pm 2.65^{\mathrm{bc}}$ & $42.40 \pm 6.66^{\mathrm{b}}$ & $18.6 \pm 3.38^{\mathrm{b}}$ \\
\hline Quinoa 10\% (CH) & $84.40 \pm 9.10^{\mathrm{de}}$ & $90.20 \pm 8.76^{\mathrm{b}}$ & $38.80 \pm 3.83^{\mathrm{ab}}$ & $24.84 \pm 13.68^{\mathrm{c}}$ & $19.7 \pm 4.16^{\mathrm{b}}$ \\
\hline (+ ve)Control (SY) $^{\mathrm{b}}$ & $110.80 \pm 7.50^{\mathrm{b}}$ & $102.40 \pm 4.72^{\mathrm{a}}$ & $34.25 \pm 1.92^{\mathrm{c}}$ & $57.85 \pm 5.69^{\mathrm{a}}$ & $20.7 \pm 2.62^{\mathrm{a}}$ \\
\hline Quinoa 5\% (SY) & $87.80 \pm 6.42^{\mathrm{cd}}$ & $85.40 \pm 9.94^{\mathrm{bc}}$ & $34.80 \pm 3.77^{\mathrm{c}}$ & $35.08 \pm 12.19^{\mathrm{bc}}$ & $17.9 \pm 3.00^{\mathrm{b}}$ \\
\hline Quinoa 10\% (SY) & $92.80 \pm 7.69^{\mathrm{cd}}$ & $89.20 \pm 8.04^{\mathrm{b}}$ & $34.50 \pm 1.12^{\mathrm{c}}$ & $38.54 \pm 7.40^{\mathrm{b}}$ & $19.8 \pm 3.56^{\mathrm{b}}$ \\
\hline
\end{tabular}

Different superscript letters in the same column denote significant differences $(<0.05)$.

\section{Histopathological examination of the heart rats}

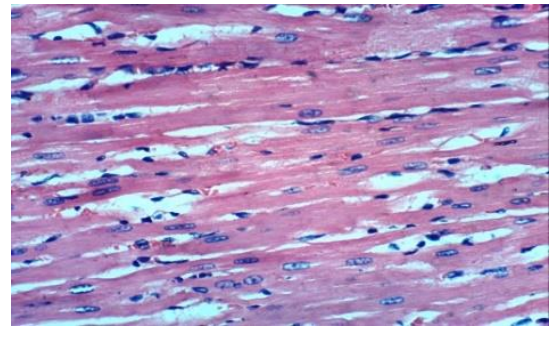

Fig(1):

Heart of rat from group (1) showing normal cardiac myocytes. $(\mathrm{H} \& \mathrm{E} \times 400)$

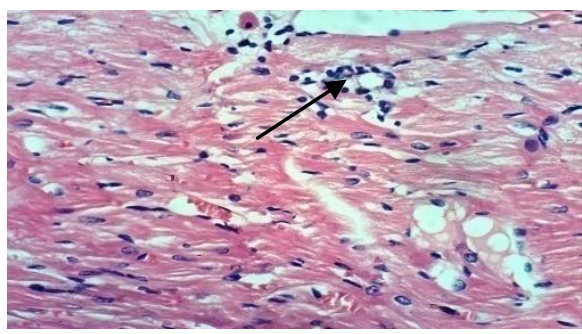

Fig(3):

Heart of rat from group (3)showing few mono unclear cells infiltration. .(H\&E×400)

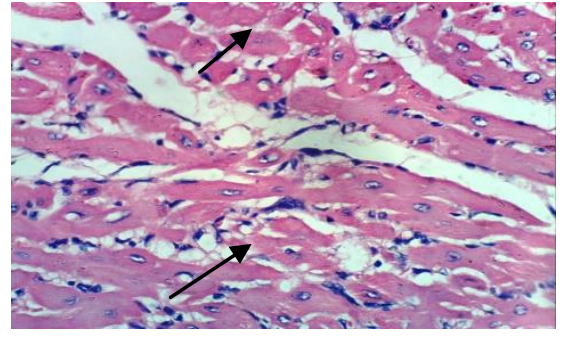

Fig(2):

Heart of rat from group (2) showing vacuolization (arrow) and myolysis (arrow head) of cardiac myocytesassociated with separation and atrophy of myocardial fibers (star).(H\&E×400)

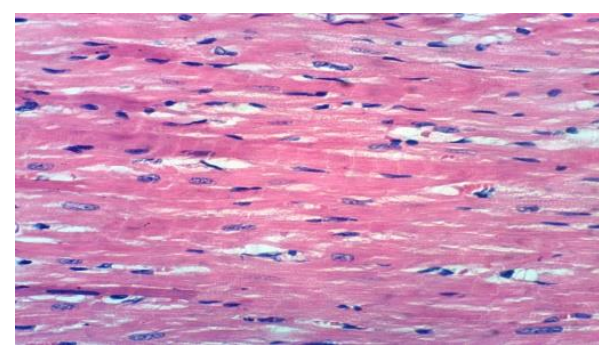

Fig (4):

Heart of rat from group (4) showing no histopathological changes. .(H\&E×400) 


\section{Rasha M. Bahnasy, et al}

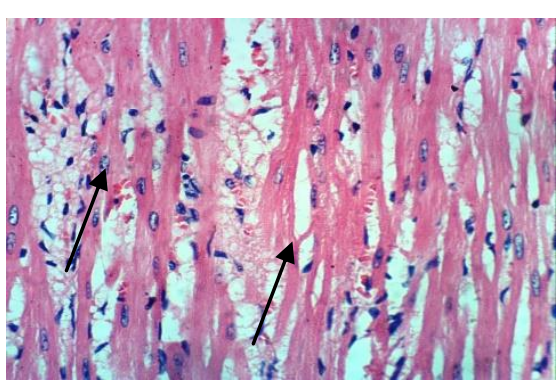

Fig (5):

Heart of rat from group (5) showing inter myocardial oedema. .(H\&E×400)

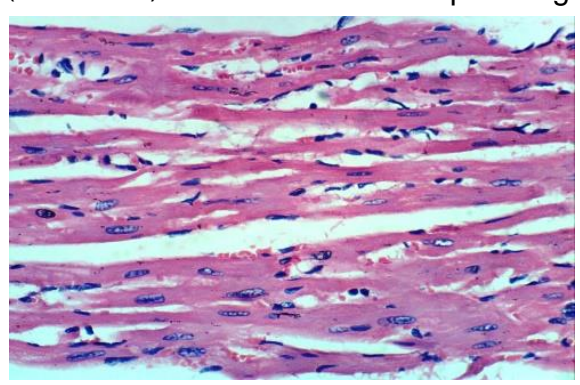

Fig (7):

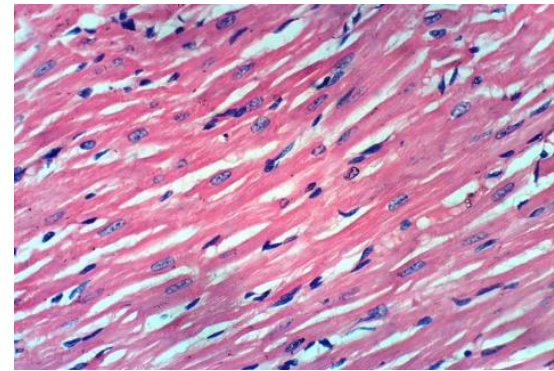

Fig (6):

Heart of rat from group (6) showing no histopathological changes. .(H\&E×400)

Heart of rat from group (7) showing no histopathological changes. (H\&E×400)

\section{Conclusion}

According to the current findings, it could be concluded that dietary supplementation with quinoa is recommended to prevent side effects of synthetic food colors. The supplementation was more potent in improvement of lipid profile. Further studies are necessary to validate these findings in a bigger population, and our findings may provide a background to reduce using of synthetic food colors because of its side effects. 


\section{References}

Abbas, J. R., \& Al-Hamadawi, H. A. (2019).

Effect of chocolate brown HT E155 on some hormones in male albino rats. EurAsian Journal of BioSciences, 13(1), 485-489.

Abd Elhalem, S., EL-Atrash, A., Osman, A., Sherif, A., \& Salim, E. (2016).

Short term toxicity of food additive azo dye, sunset yellow (E110), at low doses, in male Sprague-Dawley rats. Egypt. J. Exp. Biol. Zool, 12, 13-21.

Aboel-Zahab, H., El-Khyat, Z., Sidhom, G., Awadallah, R., Abdel-Al, W., \& Mahdy, K. (1997). Physiological effects of some synthetic food colouring additives on rats. Bollettino Chimico Farmaceutico, 136(10), 615-627.

Aguilar, F., Crebelli, R., Dusemund, B., Galtier, P., Gott, D., Gundert-Remy, U., Koenig, J., Lambre, C., Leblanc, J.-C., \& Mosesso, P. (2014).

Reconsideration of the temporary ADI and refined exposure assessment for Sunset Yellow FCF (E 110) EFSA Panel on Food Additives and Nutrient Sources added to Food (ANS). EFSA Journal, 12(7).

Ahmed, J., Thomas, L., Arfat, Y. A., \& Joseph, A. (2018). Rheological, structural and functional properties of high-pressure treated quinoa starch in dispersions. Carbohydrate Polymers, 197, 649-657.

Ajiboye, T. O., Yakubu, M. T., \& Oladiji, A. T. (2011).

Electrophilic, free radical and reactive oxygen species scavenging and detoxification potentials of Lophiraalata stem bark extract. Free Radicals and Antioxidants, 1(3), 40-47.

AL-Shinnawy, M. S. (2009).

Physiological effect of a food additive on some haematological and biochemical parameters of male albino rats. Egyptian Academic Journal of Biological Sciences. A, Entomology, 2(1), 143-151.

Al-Shinnawy, M. S., \& Elkattan, N. A. (2013).

Assessment of the changes in some diagnostic parameters in male albino rats fed on an Azo Dye. Int. J. Eenv. Sci. Eng, 4, 85-92.

Allain, C. C., Poon, L. S., Chan, C. S. G., Richmond, W., \& Fu, P. C. (1974).

Enzymatic determination of total serum cholesterol. Clinical Chemistry, 20(4), 470-475.

Arrnitage, P., \& Berry, G. (1987).

Statistical rnethods In medical research Blackwell Scientific Publications. Oxford.

Aune, D., Chan, D. S. M., Lau, R., Vieira, R., Greenwood, D. C., Kampman, E., \& Norat, T. (2011). Dietary fibre, whole grains, and risk of colorectal cancer: systematic review and doseresponse meta-analysis of prospective studies. Bmj, 343. 


\section{Rasha M. Bahnasy, et al}

Bastidas, E. G., Roura, R., Rizzolo, D. A. D., Massanés, T., \& Gomis, R. (2016).

Quinoa (Chenopodium quinoa Willd), from nutritional value to potential health benefits: an integrative review. Journal of Nutrition \& Food Sciences, 2016, Vol. 6, Num. 3.

Basu, A., \& Suresh Kumar, G. (2014).

Targeting proteins with toxic azo dyes: A microcalorimetric characterization of the interaction of the food colorant amaranth with serum proteins. Journal of Agricultural and Food Chemistry, 62(31), 7955-7962.

Campbell, J. A. (1963). Methodology of protein evaluation. RAG Nutr. Document $R, 10$.

Demirkol, O., Zhang, X., \& Ercal, N. (2012).

Oxidative effects of Tartrazine (CAS No. 1934-21-0) and New Coccin (CAS No. 2611-82-7) azo dyes on CHO cells. Journal Für Verbraucherschutz Und Lebensmittelsicherheit, 7(3), 229-236.

Drury, R. A. B., \& Wallington, E. A. (1980).

Preparation and fixation of tissues. Carleton's Histological Technique, 5, 41-54.

El-Malky, W. A., Khiralla, G. M., \& Salem, S. A. (2014). Nutritional study of some food coloring agents on experimental rats. International Journal of Nutrition and Food Sciences, 3(6), 538-544.

El Rabey, H. A., Al-Seeni, M. N., \& Amer, H. M. (2013).

Efficiency of barley bran and oat bran in ameliorating blood lipid profile and the adverse histological changes in hypercholesterolemic male rats. BioMed Research International, 2013.

Elbanna, K., Sarhan, O. M., Khider, M., Elmogy, M., Abulreesh, H. H., \& Shaaban, M. R. (2017). Microbiological, histological, and biochemical evidence for the adverse effects of food azo dyes on rats. Journal of Food and Drug Analysis, 25(3), 667-680.

Fouad, D., Alobaid, H., \& Al-Jafary, A. A. (2013).

Effect of melatonin on the oxidative stress induced by the food additive ( $\mathrm{Cl}$ Food Yellow 3) on some blood parameters and antioxidant enzymes in male rat kidney. Life Science Journal, 10(4), 343-350.

Foucault, A.-S., Even, P., Lafont, R., Dioh, W., Veillet, S., Tomé, D., Huneau, J.-F., Hermier, D., \& Quignard-Boulangé, A. (2014).

Quinoa extract enriched in 20-hydroxyecdysone affects energy homeostasis and intestinal fat absorption in mice fed a high-fat diet. Physiology \& Behavior, 128, 226-231.

Friedwald, W. T. ; Leve, R. I. and Fredrickson, D. S. (1972).

No Title"Estimation of the concentration of low-density lipoprotein separated by three different methods". Clin. Chem., 19, 499-502. 


\section{Egypt. J. of Nutrition and Health Vol. 15 No. 2 July (2020)}

Fulgoni, V. L., Dreher, M., \& Davenport, A. J. (2013).

Avocado consumption is associated with better diet quality and nutrient intake, and lower metabolic syndrome risk in US adults: results from the National Health and Nutrition Examination Survey (NHANES) 2001-2008. Nutrition Journal, 12(1), 1.

Halaby, M. S., Abdel-Rahman, M. K., \& Hassan, R. A. (2017).

Protective Influence of Quinoa on Hypercholesterolemia in Male Rats.

Hassan, G. M. (2010).

Effects of some synthetic coloring additives on DNA damage and chromosomal aberrations of rats. Arab J Biotech, 13(1), 13-24.

Hegsted, D. M., Mills, R. C., Elvehjem, C. A., \& Hart, E. B. (1941).

Choline in the nutrition of chicks. Journal of Biological Chemistry, 138, 459-466.

Helal, E. G. E., Zaahkouk, S. A. M., \& Mekkawy, H. A. (2000).

Effect of Some Food Colorants (Synthetic andNatural products) of Young Albino Rats. The Egyptian Journal of Hospital Medicine, 1(1), 103-113.

Hu, X., Gao, J., Zhang, Q., Fu, Y., Li, K., Zhu, S., \& Li, D. (2013).

Soy fiber improves weight loss and lipid profile in overweight and obese adults: a randomized controlled trial. Molecular Nutrition \& Food Research, 57(12), 2147-2154.

Johnson, W. J., Mahlberg, F. H., Rothblat, G. H., \& Phillips, M. C. (1991). Cholesterol transport between cells and high-density lipoproteins. Biochimica et Biophysica Acta (BBA)-Lipids and Lipid Metabolism, 1085(3), 273-298.

Lamiaa, A., \& Barakat, A. (2011).

Hypolipidemic and antiatherogenic effects of dietary chitosan and wheatbran in high fat-high cholesterol fed rats. Australian Journal of Basic and Applied Sciences, 5(10), 30-37.

Lamothe, L. M., Srichuwong, S., Reuhs, B. L., \& Hamaker, B. R. (2015).

Quinoa (Chenopodium quinoa W.) and amaranth (Amaranthus caudatus L.) provide dietary fibres high in pectic substances and xyloglucans. Food Chemistry, 167, 490-496.

Lopes-Virella, M. F., Stone, P., Ellis, S., \& Colwell, J. A. (1977).

Cholesterol determination in high-density lipoproteins separated by three different methods. Clinical Chemistry, 23(5), 882-884.

MA, O. (1995).

Long-term biochemical and genotoxicity studies of four synthetic food and drug colourants in mice.

Makni, M., Fetoui, H., Gargouri, N. K., Garoui, E. M., Jaber, H., Makni, J., Boudawara, T., \& Zeghal, N. (2008).

Hypolipidemic and hepatoprotective effects of flax and pumpkin seed mixture rich in $\omega-3$ and $\omega-6$ fatty acids in hypercholesterolemic rats. Food and Chemical Toxicology, 46(12), 37143720. 


\section{Rasha M. Bahnasy, et al}

Mbikay, M. (2012).

Therapeutic potential of Moringa oleifera leaves in chronic hyperglycemia and dyslipidemia: a review. Frontiers in Pharmacology, 3, 24.

Mehedi, N., Mokrane, N., Alami, O., Ainad-Tabet, S., Zaoui, C., Kheroua, O., \& Saidi, D. (2013). A thirteen week ad libitum administration toxicity study of tartrazine in Swiss mice. African Journal of Biotechnology, 12(28).

Neshe, S. A., Arefin, S., Hussain, M. S., Das, A., Karmakar, P., \& Hossain, M. S. (2016). Safety evaluation of chocolate brown dye in Swiss albino mice. J Nutr Disorders Ther, 6(195), 509-2161.

Nollet, L. M. L., \& Toldrá, F. (2012).

Food analysis by HPLC. CRC Press.

Reeves, P. G., Nielsen, F. H., \& Fahey Jr, G. C. (1993).

AIN-93 purified diets for laboratory rodents: final report of the American Institute of Nutrition ad hoc writing committee on the reformulation of the AIN-76A rodent diet. Oxford University Press.

Rovina, K., Prabakaran, P. P., Siddiquee, S., \& Shaarani, S. M. (2016). Methods for the analysis of Sunset Yellow FCF (E110) in food and beverage products-a review. TrAC Trends in Analytical Chemistry, 85, 47-56.

Sahar SA, S., \& Manal MEM, S. (2012).

The effects of using color foods of children on immunity properties and liver, kidney on rats. Food and Nutrition Sciences, 2012.

Salman, A. J. H. H. A. (2016).

The Effect Study of Using Different Concentrations of Chocolate Brown Dye (Chocolate Brown HT E155) on Some Physiological Parameters and Histological Structure of Stomach and Intestine on Albino Rats. Journal of Al-Qadisiyah for Pure Science (Quarterly), 2(21), 24-35.

Schermer, S., \& Schermer, S. (1967).

Blood morphology of laboratory animals.

Sharma, A., Goyal, R. P., Chakravarty, G., \& Sharma, S. (2005).

Haemotoxic effects of chocolate brown, a commonly used blend of permitted food colour on Swiss albino mice. Asian J Exp Sci, 19(2), 93-103.

Snedecor, G. W., \& Cochran, W. G. (1980).

Statistical method 7th Ed. The lowa State University Press, Ames, lowa, USA, 39-63.

TAKAO, T., WATANABE, N., YUHARA, K., ITOH, S., SUDA, S., TSURUOKA, Y., NAKATSUGAWA, K., \& KONISHI, Y. (2005).

Hypocholesterolemic effect of protein isolated from quinoa (Chenopodium quinoa Willd.) seeds. Food Science and Technology Research, 11(2), 161-167. 
Egypt. J. of Nutrition and Health Vol. 15 No. 2 July (2020)

Tawfek, N., Amin, H., Abdalla, A., \& Fargali, S. (2015).

Adverse effects of some food additives in adult male albino rats. Current Science International, 4(4), 525-537.

Trasande, L., Shaffer, R. M., \& Sathyanarayana, S. (2018).

Food additives and child health. Pediatrics, 142(2), e20181410.

Trinder, P., \& Ann, S. (1969).

Enzymatic colorimetric test with lipid clearing factor to determine triglyceride. Clin. Biochem, 6 , 24-27.

Vanaja, R. and Palanimuthu, M. (2014).

eEffect of organophosphorous compounds poising on the metabolism of liver. International J. of Ana., Pharma. and Biol., Sciences, 3(2), 47-50.

Vega- Gálvez, A., Miranda, M., Vergara, J., Uribe, E., Puente, L., \& Martínez, E. A. (2010). Nutrition facts and functional potential of quinoa (Chenopodium quinoa willd.), an ancient Andean grain: a review. Journal of the Science of Food and Agriculture, 90(15), 2541-2547.

Wang, J., Sun, B., \& Cao, R. (2019).

Bioactive Factors and Processing Technology for Cereal Foods. Springer.

Wang, L., Sun, J., Yi, Q., Wang, X., \& Ju, X. (2012).

Protective effect of polyphenols extract of adlay (Coix lachryma-jobi L. var. ma-yuen Stapf) on hypercholesterolemia-induced oxidative stress in rats. Molecules, 17(8), 8886-8897.

Zakaria, Z. A., Kamisan, F. H., Omar, M. H., Mahmood, N. D., Othman, F., Hamid, S. S. A., \& Abdullah, M. N. H. (2017).

Methanol extract of Dicranopteris linearis L. leaves impedes acetaminophen-induced liver intoxication partly by enhancing the endogenous antioxidant system. BMC Complementary and Alternative Medicine, 17(1), 271.

Zevallos, V. F., Herencia, I. L., Chang, F., Donnelly, S., Ellis, J. H., \& Ciclitira, P. J. (2014). Gastrointestinal Effects of Eating Quinoa (Chenopodium quinoaWilld.) in Celiac Patients. American Journal of Gastroenterology, 109(2), 270-278. 
Rasha M. Bahnasy, et al

تأثير الكينوا على مستوى دهون الدم في الجرذان المعرضة لبعض ملونات الطعام الصناعية

\title{
رشا محمد بهنسي 1,2 إيمان محمود راغب3
}

\author{
1 قسم التغذية و علوم الأطعمة- كلية الاقتصاد المنزلي- جامعة الأز هر -مصر

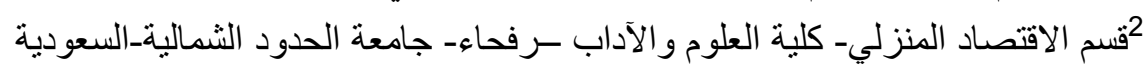

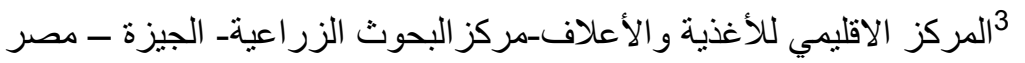 \\ المستخلص العربي
}

تشثير الدلائل العلمية المتزايدة إلى احتمال وجود تأثير ات ضارة على صحة الأطفال اتجة عن استخدام المواد

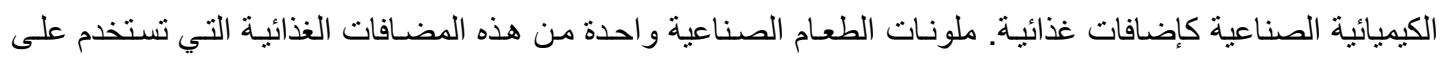

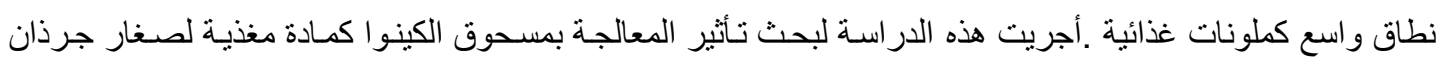

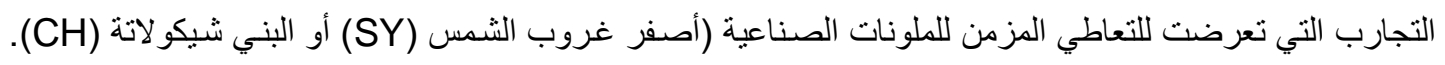

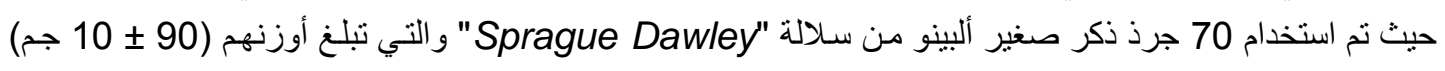

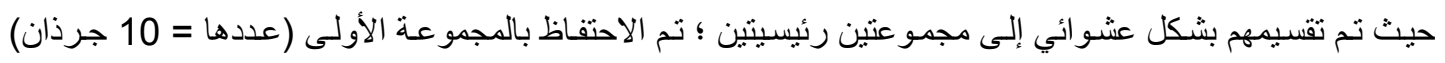

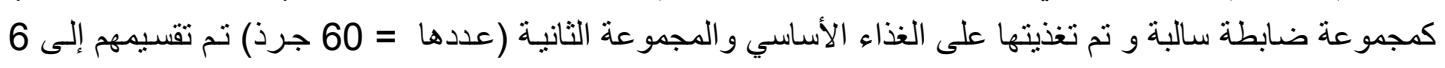

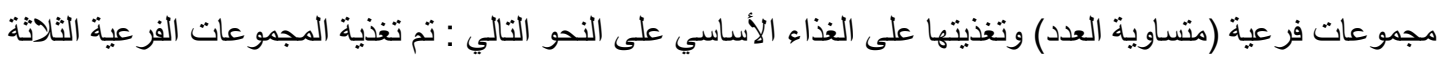

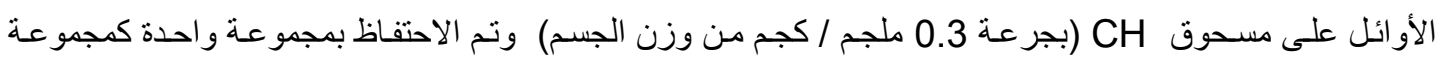

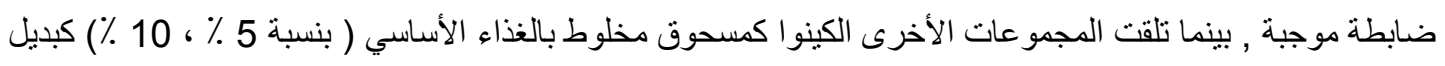

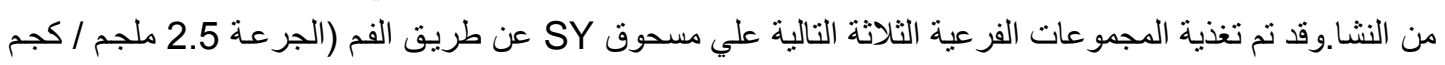

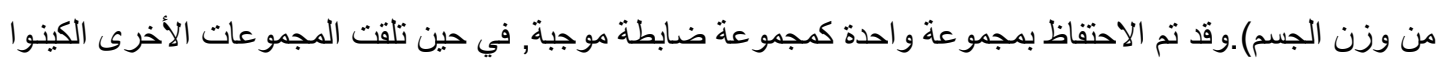

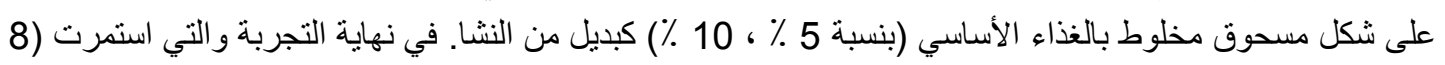

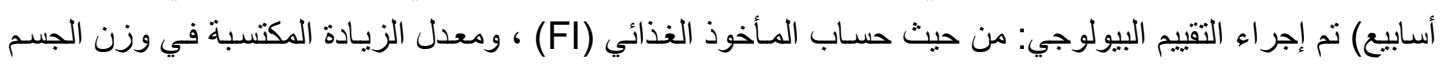

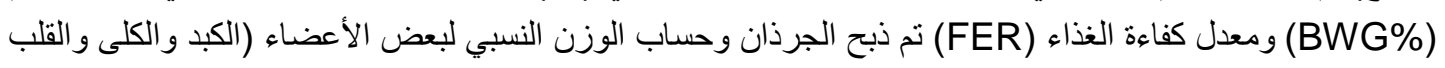

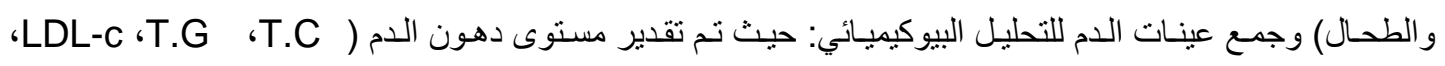

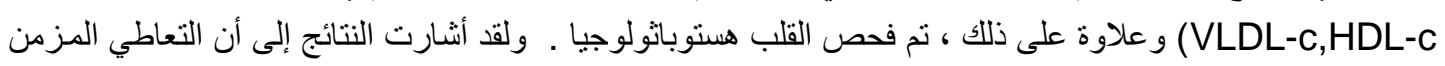

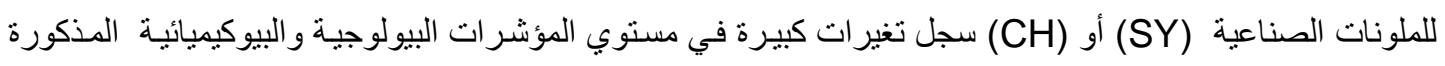

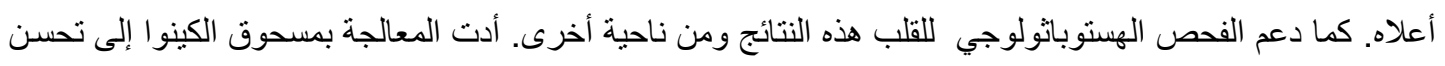

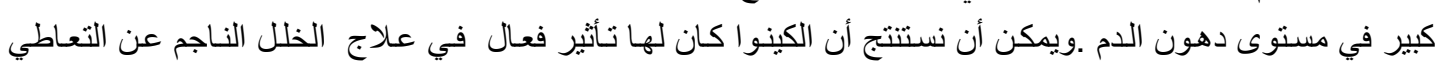

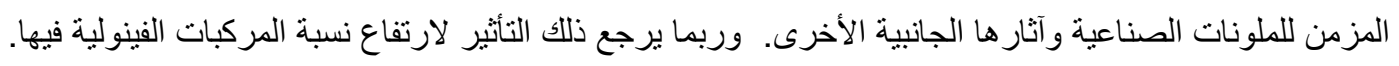

الكلمات المفتاحية: الألوان الصناعية ،بني الثيكو لاتة ،أصفر غروب الثمس ، الكينوا ، دهون الدم . 